\title{
PEMATAHAN DORMANSI BENIH TANJUNG (Mimusops elengi L.) SECARA FISIK DAN KIMIAWI DAN HUBUNGANNYA TERHADAP VIABILITAS DAN VIGOR
}

\author{
Breaking Dormancy of Spanish Cherry (Mimusops elengi L.) through Physical and Chemical \\ and Its Related to Viability and Vigour \\ Halimursyadah $^{1 *}$, Trisda Kurniawan ${ }^{1}$, Nazia Ulfa ${ }^{2}$ \\ ${ }^{1}$ Program Studi Agroteknologi Fakultas Pertanian Universitas Syiah Kuala, Darussalam \\ 23111 \\ ${ }^{2}$ Mahasiswa Program Studi Agroteknologi Fakultas Pertanian Universitas Syiah Kuala \\ 23111 \\ ${ }^{*}$ Email Korespondensi : rhalimursyadah@yahoo.com
}

\begin{abstract}
Mimusops elengi is a medium-sized evergreen tree found in tropical forests in South Asia, Southeast Asia and Northern Australia. Its timber is valuable, the fruit is edible, and it is used in traditional medicine. As the trees give thick shade and flowers emit fragrance, it is a prized collection of gardens. The problem of this plant is its seed that has dormancy. Dormancy fulfills an important function for plants since it allows seeds to survive conditions and seasons that are unfavorable for seedling growth. This study aims to determine the interaction treatment of physical and chemical in solving dormancy on the M. elengi seed. The experiment was conducted at Laboratory of Seed Science and Technology at Juni to October 2017. There were two factors that were studied, namely the first factor of physical treatment by soaking the seeds in hot water with the level of 0,60,120, and 180 hours and the second factor of chemical treatment using 97\% sulfuric acid with level 0, 10, 20 and 30\%. The parameters measured were maximum growth potential, germination capability, vigor index, relative speed of growth, simultaneously of growth, time to reach $50 \%$ germination total and dormancy intensity. The conclusions of this study are the best soaking duration for dormancy seed breaking of $\mathrm{M}$. elengi is in water at $60{ }^{\circ} \mathrm{C}$ for 180 minutes. The best concentration of sulfuric acid for breaking seed dormancy is $20 \%$. There was a significant interaction between the duration of soaking in hot water and the concentration of sulfuric acid on all observed parameters. The best combination was found at duration of soaking of 180 minutes in hot water $60^{\circ} \mathrm{C}$ and sulfuric acid concentration $20 \%$ can accelerate germination of $M$. elengi seeds from 90 days (without treatment) to 24 days (after treatment). There was an increase in germination capability from $20 \%$ to $68 \%$, maximum growth potential $73.33 \%$, vigor index $33.33 \%$, relative speed of growth $67.31 \%$, simultaneously of growth $61.31 \%$, time to reach $50 \%$ germination total 31.50 days and dormancy intensity $2.66 \%$.
\end{abstract}

Keywords: Dormancy, physical and chemical, spanish cherry, viability, vigor 


\section{PENDAHULUAN}

Tanaman tanjung (Mimusops elengi L.) merupakan tanaman tahunan dari famili Sapotaceae yang berasal dari Asia Selatan, Asia Tenggara dan Australia Utara. Tanaman ini merupakan salah satu jenis tanaman peneduh karena bentuk tajuknya yang rimbun dan daunnya selalu hijau. Banyaknya manfaat dari tanaman tanjung, seperti kayunya bernilai jual tinggi, buahnya dapat digunakan sebagai obat dan kulit buahnya dapat diekstraksi sebagai bahan tambahan dalam pembuatan plastik dan efektif sebagai penyerap polutan (MaiHong et al. 2006; Heyne 1987).

Perbanyakan tanaman tanjung dapat dilakukan baik secara vegetatif yaitu dengan stek batang maupun generatif dengan menggunakan benih. Namun perbanyakan menggunakan benih terdapat banyak hambatan yaitu waktu yang lama dan persentase perkecambahan yang rendah. Benih tanjung memiliki kulit biji yang keras dan pada daging buah yang tebal terdapat senyawa aromatik inhibitor yang menghasilkan aroma tertentu didalam biji yang menjadikan salah satu faktor penyebab dormansi (Winarni 2014). Masa dormansi dapat berlangsung antara 2.5 hingga 3 bulan (Widhityarini et al. 2013). Kulit benih yang sangat keras menyebabkan impermeabilitas terhadap air dan gas $\mathrm{O}_{2}$. Upaya pematahan dormansi dapat dilakukan secara fisik yaitu skarifikasi, perendaman air panas dan pelukaan di sekitar embrio serta dapat dilakukan juga secara kimiawi yaitu penggunaan $\mathrm{H}_{2} \mathrm{SO}_{4}, \quad \mathrm{KNO}_{3}, \mathrm{HCl}$ dan hormon Giberelin (Sandi et al. 2014).

Perendaman benih dalam air panas merupakan salah satu proses yang dapat mematahkan dormansi pada biji berkulit keras. Proses ini dapat menguraikan kandungan lignin pada pericarp sehingga menjadi lebih lunak dan prosesa imbibisi mudah terjadi (Fitri 2015). Hasil penelitian Ani (2006), perendaman benih lamtoro (Leucaena leucocephala) dalam air panas berpengaruh sangat nyata terhadap daya kecambah yang ditunjukkan dengan pertumbuhan normal yang baik yaitu pada perlakuan suhu awal air $60{ }^{\circ} \mathrm{C}$ selama 90 menit yang memiliki persentase perkecambahan $75 \%$ dibandingkan dengan kontrol, 30 menit dan 60 menit.

Pematahan dormansi secara kimiawi dapat menggunakan larutan asam sulfat pekat $\left(\mathrm{H}_{2} \mathrm{SO}_{4}\right)$. Perlakuan larutan $\mathrm{H}_{2} \mathrm{SO}_{4}$ yang diberikan pada benih mampu melunakkan endokarp dan membuang zat penghambat yang ada pada benih sehingga mengakibatkan endosperm mampu menyerap $\mathrm{O}_{2}$ dan $\mathrm{CO}_{2}$ serta proses imbibisi dapat berlangsung (Suyatmi et al. 2008). Penggunaan $\mathrm{H}_{2} \mathrm{SO}_{4} \quad 20 \%$ dapat mematahkan dormansi pada benih aren (Arenga pinnata) dan meningkatkan potensi tumbuh $83.33 \%$, daya kecambah $46.67 \%$, nilai penundaan perkecambahan $16.67 \%$ dan indeks vigor $26.67 \%$ (Rahayu 2013).

Berdasarkan uraian di atas maka perlu dilakukan penelitian tentang pematahan dormansi akibat lama perendaman benih dalam air panas dan konsentrasi asam sulfat terhadap viabilitas dan vigor benih tanjung (Mimusops elengi L.).

\section{BAHAN DAN METODE PENELITIAN}

\section{Tempat dan Waktu}

Penelitian ini dilaksanakan di Laboratorium Ilmu dan Teknologi Benih, Program Studi Agroteknologi, Fakultas Pertanian Universitas Syiah Kuala, Darussalam Banda Aceh, yang berlangsung dari bulan Juni sampai Oktober 2017. 


\section{Bahan dan Alat}

Bahan yang digunakan adalah benih tanjung 1200 butir dengan ciri masak fisiologis dengan warna kulit benih merah kekuningan yang diperoleh di kawasan kampus Universitas Syiah Kuala, aquades $(600 \mathrm{ml})$, asam sulfat $\left(\mathrm{H}_{2} \mathrm{SO}_{4}\right)$ pekat $97 \%$ (123.6 ml) dan pasir kuarsa sebagai media perkecambahan. Alat yang digunakan dalam penelitian ini adalah pipet tetes, gelas ukur $500 \mathrm{ml}$, media perkecambahan, beaker glass $500 \mathrm{ml}$, hand sprayer, oven, ayakan 9 mesh, kertas label, alat tulis, kalkulator, lembar pencatatan data dan kamera.

\section{Pelaksanaan Penelitian}

Penelitian ini didesain
menggunakan Rancangan Acak Lengkap (RAL) faktorial dengan dua faktor. Faktor pertama adalah lama perendaman air panas yaitu tanpa perendaman (kontrol), 60, 120 dan 180 menit dan faktor kedua konsentrasi $\mathrm{H}_{2} \mathrm{SO}_{4}$ yaitu $0 \%, 10 \%, 20 \%$ dan $30 \%$. Secara keseluruhan terdapat 16 kombinasi perlakuan dengan 3 kali ulangan, sehingga diperoleh 48 satuan percobaan, masing masing ditanam 25 butir benih tiap unit percobaan.

Parameter yang diamati dalam penelitian ini adalah potensi tumbuh maksimum, daya berkecambah, indeks vigor, kecepatan tumbuh, keserempakan tumbuh, intensitas dormansi. Potensi Tumbuh Maksimum yaitu jumlah benih menunjukkan gejala tumbuh pada hitungan terakhir atau final count (hari ke70). Daya Berkecambah diamati dengan menghitung jumlah benih yang berkecambah normal pada hitungan pertama atau first count (hari ke-45) dan hitungan terakhir. Benih dikatakan berkecambah normal apabila akar primer tumbuh normal, plumula berkembang baik dan memiliki dua daun serta hipokotil tumbuh tegak. Indeks Vigor merupakan vigor kekuatan tumbuh benih dihitung berdasarkan persentase kecambah normal pada hitungan pertama. Kecepatan tumbuh relatif menggambarkan vigor kekuatan tumbuh benih, yaitu perbandingan antara nilai $\mathrm{K}_{\mathrm{CT}}$ dengan $\mathrm{K}_{\mathrm{CT}}$ maksimum. $\mathrm{K}_{\mathrm{CT}}$ maksimum diperoleh dari asumsi bahwa pada saat hitungan pertama kecambah normal sudah mencapai $100 \%$. Kecepatan tumbuh dihitung berdasarkan total tambahan kecambah normal setiap hari. Pengamatan dilakukan setiap hari selama waktu perkecambahan 70 hari. Keserempakan tumbuh menggambarkan vigor kekuatan tumbuh benih diperoleh dengan menghitung jumlah kecambah normal diantara hitungan pertama dan hitungan terakhir (hari ke-57). Waktu yang dibutuhkan untuk mencapai $50 \%$ perkecambahan dihitung berdasarkan jumlah benih yang berkecambah setiap harinya, hingga mencapai $50 \%$ dari total perkecambahan. Intensitas dormansi yang tinggi menunjukkan bahwa benih diuji dengan perlakuan tersebut memiliki tingkat perkecambahan yang rendah yang dinyatakan dalam persen.

\section{HASIL DAN PEMBAHASAN}

Interaksi antara perlakuan fisik dan kimiawi dalam pematahan dormansi benih tanjung dan hubungannya terhadap nilai viabilitas dan vigor

Rata-rata interaksi nilai viabilitas dan vigor benih tanjung akibat perlakuan fisik dan kimiawi disajikan pada Tabel 1. 
Tabel 1. Rata-rata nilai viabilitas dan vigor benih tanjung akibat perlakuan fisik dan kimiawi

\begin{tabular}{|c|c|c|c|c|}
\hline \multirow{3}{*}{ Perlakuan } & \multicolumn{4}{|c|}{ Potensi Tumbuh Maksimum (\%) } \\
\hline & \multicolumn{4}{|c|}{ Konsentrasi Asam Sulfat (\%) } \\
\hline & $0\left(\mathrm{H}_{0}\right)$ & $10\left(\mathrm{H}_{1}\right)$ & $20\left(\mathrm{H}_{2}\right)$ & $30\left(\mathrm{H}_{3}\right)$ \\
\hline Kontrol $\left(\mathrm{L}_{0}\right)$ & $\begin{array}{l}26.56 \mathrm{c} \\
(20.00)\end{array}$ & $\begin{array}{l}31.94 \text { cde } \\
(28.00)\end{array}$ & $\begin{array}{c}37.65 \text { efgh } \\
(37.33)\end{array}$ & $\begin{array}{c}39.99 \text { fghi } \\
(41.33)\end{array}$ \\
\hline 60 menit $\left(\mathrm{L}_{1}\right)$ & $\begin{array}{l}27.48 \mathrm{c} \\
((21.33)\end{array}$ & $\begin{array}{c}\text { 35.25defg } \\
(33.33)\end{array}$ & $\begin{array}{l}46.91 \mathrm{ij} \\
(53.33)\end{array}$ & $\begin{array}{c}32.77 \mathrm{cdef} \\
(29.33)\end{array}$ \\
\hline 120 menit $\left(\mathrm{L}_{2}\right)$ & $\begin{array}{c}28.41 \mathrm{~cd} \\
(22.66)\end{array}$ & $\begin{array}{c}\text { 42.32 ghi } \\
(45.33)\end{array}$ & $\begin{array}{l}51.55 \mathrm{jk} \\
(61.33)\end{array}$ & $\begin{array}{l}9.51 \mathrm{~b} \\
(4.00)\end{array}$ \\
\hline 180 menit $\left(\mathrm{L}_{3}\right)$ & $\begin{array}{c}33.61 \mathrm{cdef} \\
(30.66)\end{array}$ & $\begin{array}{c}44.61 \mathrm{hij} \\
(49.33)\end{array}$ & $\begin{array}{l}58.92 \mathrm{k} \\
(73.33) \\
\end{array}$ & $\begin{array}{c}0.57 \mathrm{a} \\
(0)\end{array}$ \\
\hline BNJ 0.05 & & & & \\
\hline \multirow{3}{*}{ Perlakuan } & \multicolumn{4}{|c|}{ Daya Berkecambah (\%) } \\
\hline & \multicolumn{4}{|c|}{ Konsentrasi Asam Sulfat } \\
\hline & $0\left(\mathrm{H}_{0}\right)$ & $10\left(\mathrm{H}_{1}\right)$ & $20\left(\mathrm{H}_{2}\right)$ & $30\left(\mathrm{H}_{3}\right)$ \\
\hline Kontrol $\left(\mathrm{L}_{0}\right.$ & $\begin{array}{l}26.56 \mathrm{c} \\
(20.00) \\
\end{array}$ & $\begin{array}{c}30.20 \mathrm{cde} \\
(25.33)\end{array}$ & $\begin{array}{l}35.25 \mathrm{ef} \\
(33.33)\end{array}$ & $\begin{array}{c}36.84 \mathrm{fg} \\
(36.00)\end{array}$ \\
\hline 60 menit $\left(\mathrm{L}_{1}\right)$ & $\begin{array}{l}26.56 \mathrm{c} \\
(20.00)\end{array}$ & $\begin{array}{c}33.61 \mathrm{def} \\
(30.66)\end{array}$ & $\begin{array}{l}44.61 \mathrm{hi} \\
(49.33)\end{array}$ & $\begin{array}{c}29.88 \text { cde } \\
(24.00)\end{array}$ \\
\hline 120 menit $\left(\mathrm{L}_{2}\right)$ & $\begin{array}{c}27.48 \mathrm{~cd} \\
(21.33)\end{array}$ & $\begin{array}{c}41.55 \mathrm{gh} \\
(44.00)\end{array}$ & $\begin{array}{l}48.44 \mathrm{i} \\
(56.00) \\
\end{array}$ & $\begin{array}{l}7.88 \mathrm{~b} \\
(2.66)\end{array}$ \\
\hline 180 menit $\left(\mathrm{L}_{3}\right)$ & $\begin{array}{c}31.94 \mathrm{cdef} \\
(28.00)\end{array}$ & $\begin{array}{c}43.85 \mathrm{hi} \\
(48.00)\end{array}$ & $\begin{array}{l}55.58 \mathrm{j} \\
(68.00) \\
\end{array}$ & $\begin{array}{c}0.57 \mathrm{a} \\
(0)\end{array}$ \\
\hline BNJ 0,05 & & & & \\
\hline \multirow{3}{*}{ Perlakuan } & \multicolumn{4}{|c|}{ Indeks Vigor(\%) } \\
\hline & \multicolumn{4}{|c|}{ Konsentrasi Asam Sulfat } \\
\hline & $0\left(\mathrm{H}_{0}\right)$ & $10\left(\mathrm{H}_{1}\right)$ & $20\left(\mathrm{H}_{2}\right)$ & $30\left(\mathrm{H}_{3}\right)$ \\
\hline Kontrol $\left(\mathrm{L}_{0}\right.$ & $\begin{array}{c}14.79 \mathrm{~cd} \\
(6.66)\end{array}$ & $\begin{array}{c}17.70 \mathrm{cdef} \\
(9.33)\end{array}$ & $\begin{array}{c}22.47 \text { efg } \\
(14.66)\end{array}$ & $\begin{array}{c}22.47 \mathrm{efg} \\
(14.66)\end{array}$ \\
\hline 60 menit $\left(\mathrm{L}_{1}\right)$ & $\begin{array}{c}13.16 \mathrm{bc} \\
(5.33)\end{array}$ & $\begin{array}{c}20.26 \text { def } \\
(12.00)\end{array}$ & $\begin{array}{c}28.41 \mathrm{gh} \\
(22.66)\end{array}$ & $\begin{array}{c}20.26 \mathrm{def} \\
(12.00)\end{array}$ \\
\hline 120 menit $\left(\mathrm{L}_{2}\right)$ & $\begin{array}{c}16.42 \mathrm{cde} \\
(8.00)\end{array}$ & $\begin{array}{c}23.57 \mathrm{fg} \\
(16.00)\end{array}$ & $\begin{array}{l}31.94 \mathrm{hi} \\
(28.00)\end{array}$ & $\begin{array}{l}7.88 \mathrm{~b} \\
(2.66)\end{array}$ \\
\hline 180 menit $\left(\mathrm{L}_{3}\right)$ & $\begin{array}{c}18.98 \mathrm{cdef} \\
(10.66)\end{array}$ & $\begin{array}{c}27.48 \mathrm{gh} \\
(21.33)\end{array}$ & $\begin{array}{l}35.25 \mathrm{i} \\
(33.33)\end{array}$ & $\begin{array}{c}0.57 \mathrm{a} \\
(0)\end{array}$ \\
\hline BNJ 0,05 & & & & \\
\hline \multirow{3}{*}{ Perlakuan } & \multicolumn{4}{|c|}{ Kecepatan Tumbuh Relatif(\%) } \\
\hline & \multicolumn{4}{|c|}{ Konsentrasi Asam Sulfat } \\
\hline & $0\left(\mathrm{H}_{0}\right)$ & $10\left(\mathrm{H}_{1}\right)$ & $20\left(\mathrm{H}_{2}\right)$ & $30\left(\mathrm{H}_{3}\right)$ \\
\hline Kontrol $\left(\mathrm{L}_{0}\right)$ & $\begin{array}{l}24.59 \mathrm{c} \\
(17.32)\end{array}$ & $\begin{array}{l}29.03 \mathrm{cdef} \\
(23.58)\end{array}$ & $\begin{array}{c}34.20 \mathrm{fg} \\
(31.61)\end{array}$ & $\begin{array}{c}35.36 \mathrm{fg} \\
(33.54)\end{array}$ \\
\hline 60 menit $\left(\mathrm{L}_{1}\right)$ & $\begin{array}{c}25.06 \mathrm{~cd} \\
(17.98)\end{array}$ & $\begin{array}{c}32.39 \text { ef } \\
(28.71)\end{array}$ & $\begin{array}{l}43.52 \mathrm{~h} \\
(47.43)\end{array}$ & $\begin{array}{c}28.99 \mathrm{cdef} \\
(23.49)\end{array}$ \\
\hline
\end{tabular}




\begin{tabular}{|c|c|c|c|c|}
\hline $120 \operatorname{menit}\left(\mathrm{L}_{2}\right)$ & $\begin{array}{c}26.33 \mathrm{cde} \\
(19.69)\end{array}$ & $\begin{array}{c}39.86 \mathrm{gh} \\
(41.03)\end{array}$ & $\begin{array}{l}48.23 \mathrm{~h} \\
(55.62) \\
\end{array}$ & $\begin{array}{l}8.63 \mathrm{~b} \\
(3.20)\end{array}$ \\
\hline 180 menit $\left(\mathrm{L}_{3}\right)$ & $\begin{array}{c}31.48 \mathrm{def} \\
(27.30)\end{array}$ & $\begin{array}{c}43.41 \mathrm{gh} \\
(45.51)\end{array}$ & $\begin{array}{l}55.15 \mathrm{i} \\
(67.31)\end{array}$ & $\begin{array}{c}0.57 \mathrm{a} \\
(0)\end{array}$ \\
\hline BNJ 0,05 & \multicolumn{4}{|c|}{6.64} \\
\hline \multirow{3}{*}{ Perlakuan } & \multicolumn{4}{|c|}{ Keserempakan Tumbuh (\%) } \\
\hline & \multicolumn{4}{|c|}{ Konsentrasi Asam Sulfat } \\
\hline & $0\left(\mathrm{H}_{0}\right)$ & $10\left(\mathrm{H}_{1}\right)$ & $20\left(\mathrm{H}_{2}\right)$ & $30\left(\mathrm{H}_{3}\right)$ \\
\hline Kontrol $\left(\mathrm{L}_{0}\right)$ & $\begin{array}{l}21.36 \mathrm{c} \\
(13.33) \\
\end{array}$ & $\begin{array}{c}29.28 \mathrm{def} \\
(24.00)\end{array}$ & $\begin{array}{c}33.61 \mathrm{fg} \\
(30.66)\end{array}$ & $\begin{array}{c}33.61 \mathrm{fg} \\
(30.66)\end{array}$ \\
\hline 60 menit $\left(\mathrm{L}_{1}\right)$ & $\begin{array}{c}23.57 \mathrm{~cd} \\
(16.00)\end{array}$ & $\begin{array}{c}32.77 \mathrm{fg} \\
(29.33) \\
\end{array}$ & $\begin{array}{l}41.55 \mathrm{~h} \\
(44.00) \\
\end{array}$ & $\begin{array}{c}29.33 \mathrm{def} \\
(24.00)\end{array}$ \\
\hline 120 menit $\left(L_{2}\right)$ & $\begin{array}{c}25.56 \mathrm{cde} \\
(18.66)\end{array}$ & $\begin{array}{c}38.44 \mathrm{gh} \\
(38.66)\end{array}$ & $\begin{array}{l}44.61 \mathrm{~h} \\
(49.33)\end{array}$ & $\begin{array}{l}7.88 \mathrm{~b} \\
(2.66)\end{array}$ \\
\hline 180 menit $\left(\mathrm{L}_{3}\right)$ & $\begin{array}{c}31.07 \text { ef } \\
(26.66)\end{array}$ & $\begin{array}{c}39.21 \mathrm{gh} \\
(40.00)\end{array}$ & $\begin{array}{l}51.55 \mathrm{i} \\
(61.33) \\
\end{array}$ & $\begin{array}{c}0.57 \mathrm{a} \\
(0)\end{array}$ \\
\hline BNJ 0,05 & \multicolumn{4}{|c|}{6.48} \\
\hline \multirow{3}{*}{ Perlakuan } & \multicolumn{4}{|c|}{ Waktu yang dibutuhkan untuk mencapai $50 \%$ total perkecambahan(Hari) } \\
\hline & \multicolumn{4}{|c|}{ Konsentrasi Asam Surfat } \\
\hline & $0\left(\mathrm{H}_{0}\right)$ & $10\left(\mathrm{H}_{1}\right)$ & $20\left(\mathrm{H}_{2}\right)$ & $30\left(\mathrm{H}_{3}\right)$ \\
\hline Kontrol $\left(\mathrm{L}_{0}\right)$ & $\begin{array}{l}36.56 \mathrm{a} \\
(35.50)\end{array}$ & $\begin{array}{l}34.75 \mathrm{a} \\
(32.50)\end{array}$ & $\begin{array}{l}34.31 \mathrm{a} \\
(31.80)\end{array}$ & $\begin{array}{l}34.75 \mathrm{a} \\
(32.50)\end{array}$ \\
\hline 60 menit $\left(\mathrm{L}_{1}\right)$ & $\begin{array}{l}35.77 \mathrm{a} \\
(34.16)\end{array}$ & $\begin{array}{l}35.41 \mathrm{a} \\
(33.58)\end{array}$ & $\begin{array}{l}34.95 \mathrm{a} \\
(33.83)\end{array}$ & $\begin{array}{l}33.51 \mathrm{a} \\
(30.50)\end{array}$ \\
\hline 120 menit $\left(\mathrm{L}_{2}\right)$ & $\begin{array}{l}35.56 \mathrm{a} \\
(33.83)\end{array}$ & $\begin{array}{l}35.73 \mathrm{a} \\
(34.11)\end{array}$ & $\begin{array}{l}34.13 \mathrm{a} \\
(31.50)\end{array}$ & $\begin{array}{l}19.29 \mathrm{~b} \\
(15.33)\end{array}$ \\
\hline 180 menit $\left(\mathrm{L}_{3}\right)$ & $\begin{array}{l}35.16 \mathrm{a} \\
(33.16) \\
\end{array}$ & $\begin{array}{l}34.75 \mathrm{a} \\
(32.50) \\
\end{array}$ & $\begin{array}{l}34.14 \mathrm{a} \\
(31.50) \\
\end{array}$ & $\begin{array}{c}0.57 \mathrm{c} \\
(0)\end{array}$ \\
\hline \multirow[t]{2}{*}{ Perlakuan } & \multicolumn{4}{|c|}{ Intensitas Dormansi $(\%)$} \\
\hline & $0\left(\mathrm{H}_{0}\right)$ & $10\left(\mathrm{H}_{1}\right)$ & $20\left(\mathrm{H}_{2}\right)$ & $30\left(\mathrm{H}_{3}\right)$ \\
\hline Kontrol $\left(\mathrm{L}_{0}\right)$ & $\begin{array}{l}38.44 \mathrm{a} \\
(38.66)\end{array}$ & $\begin{array}{c}30.20 \mathrm{bcd} \\
(25.33)\end{array}$ & $\begin{array}{c}23.57 \mathrm{defg} \\
(16.00)\end{array}$ & $\begin{array}{c}20.26 \mathrm{fgh} \\
(12.00)\end{array}$ \\
\hline 60 menit $\left(\mathrm{L}_{1}\right)$ & $\begin{array}{c}35.25 \mathrm{ab} \\
(33.33)\end{array}$ & $\begin{array}{c}28.41 \mathrm{bcd} \\
(22.66)\end{array}$ & $\begin{array}{c}21.36 \mathrm{efgh} \\
(13.33)\end{array}$ & $\begin{array}{c}17.70 \mathrm{gh} \\
(9.33)\end{array}$ \\
\hline 120 menit $\left(\mathrm{L}_{2}\right)$ & $\begin{array}{c}34.44 \mathrm{ab} \\
(32.00)\end{array}$ & $\begin{array}{c}27.48 \mathrm{cde} \\
(21.33)\end{array}$ & $\begin{array}{c}16.42 \mathrm{~h} \\
(8.00)\end{array}$ & $\begin{array}{l}4.22 \mathrm{ij} \\
(1.33)\end{array}$ \\
\hline 180 menit $\left(\mathrm{L}_{3}\right)$ & $\begin{array}{c}33.61 \mathrm{abc} \\
(30.66)\end{array}$ & $\begin{array}{c}25.56 \mathrm{def} \\
(18.66)\end{array}$ & $\begin{array}{l}7.88 \mathrm{i} \\
(2.66)\end{array}$ & $\begin{array}{c}0.57 \mathrm{j} \\
(0)\end{array}$ \\
\hline
\end{tabular}

Keterangan : Angka yang diikuti oleh huruf yang sama pada baris dan kolom yang sama tidak berbeda nyata pada tingkat peluang 0.05 (Uji BNJ). ( ) = angka sebelum transformasi 
Tabel 1 menunjukkan bahwa peningkatan lama perendaman dari kontrol hingga 180 menit dalam air panas suhu $60^{\circ} \mathrm{C}$ untuk perlakuan fisik pada parameter viabilitas dan vigor menunjukkan perbaikan terhadap persentase perkecambahan benih tanjung dari $20 \%$ menjadi $68 \%$. Pada perlakuan ini terjadi pelunakan testa atau kulit benih sehingga menjadi permeabel untuk dilalui oleh air dan gas. Hal ini sesuai dengan penelitian Kurnianingsih (2012), pada benih ki hijau (Samanea saman) memiliki persentase kecambah mencapai $56.12 \%$ akibat perendaman air panas pada suhu $60^{\circ} \mathrm{C}$ dibandingkan dengan perendaman air panas pada suhu $30^{\circ} \mathrm{C}, 40^{\circ} \mathrm{C}$ dan $50^{\circ} \mathrm{C}$ yang hanya memiliki persentase kecambah rata-rata $39.46 \%$. Puspitarini (2003) juga menambahkan benih akibat direndam dalam air panas menyebabkan terurainya tannin dan lignin yang terdapat pada kulit benih sehingga kulit benih menjadi lebih lunak serta proses imbibisi dapat terjadi pada benih. Namun demikian perlakuan fisik ini harus dikombinasikan dengan perlakuan kimia dengan memberi larutan asam sulfat pekat untuk memperbaiki persentase perkecambahan agar lebih meningkat. Penambahan konsentrasi asam sulfat dari kontrol hingga $20 \%$ telah menunjukkan peningkatan perkecambahan benih tanjung. Penambahan konsentrasi asam sulfat pekat menjadi $30 \%$ tidak diikuti dengan peningkatan daya berkecambahnya. Hal ini sesuai dengan penelitian Rahayu (2013), menyatakan bahwa benih aren (Arenga pinnata) yang direndam dalam larutan $\mathrm{H}_{2} \mathrm{SO}_{4}$ dengan konsentrasi $20 \%$ dan lama perendaman 20 menit dapat meningkatkan nilai potensi tumbuh maksimum, daya berkecambah, nilai penundaan perkecambahan dan indeks vigor. Meningkatnya permeabilitas pada permukaan kulit benih disebabkan oleh larutnya sebagian komponen lignin kulit benih, sehingga air lebih mudah masuk ke dalam benih untuk merangsang pertumbuhan embrio pada proses perkecambahan. Neto (2000) juga menjelaskan bahwa asam sulfat berkerja pada bagian kutikula yang dapat melarutkan lignin pada benih sehingga kulit benih menjadi lebih lunak serta air maupun gas dapat masuk ke dalam benih sehingga terjadinya proses perkecambahan pada benih.

Interaksi antara perlakuan fisik dan kimia pada pematahan dormansi benih tanjung terhadap nilai viabilitas dan vigor disajikan pada Gambar 1, 2, 3, 4, 5,6, dan 7. Secara umum kombinasi perlakuan fisik dan kimia terbaik dijumpai pada perlakuan lama perendaman 120 menit pada konsentrasi $20 \%$ terhadap semua parameter viabilitas dan vigor. 


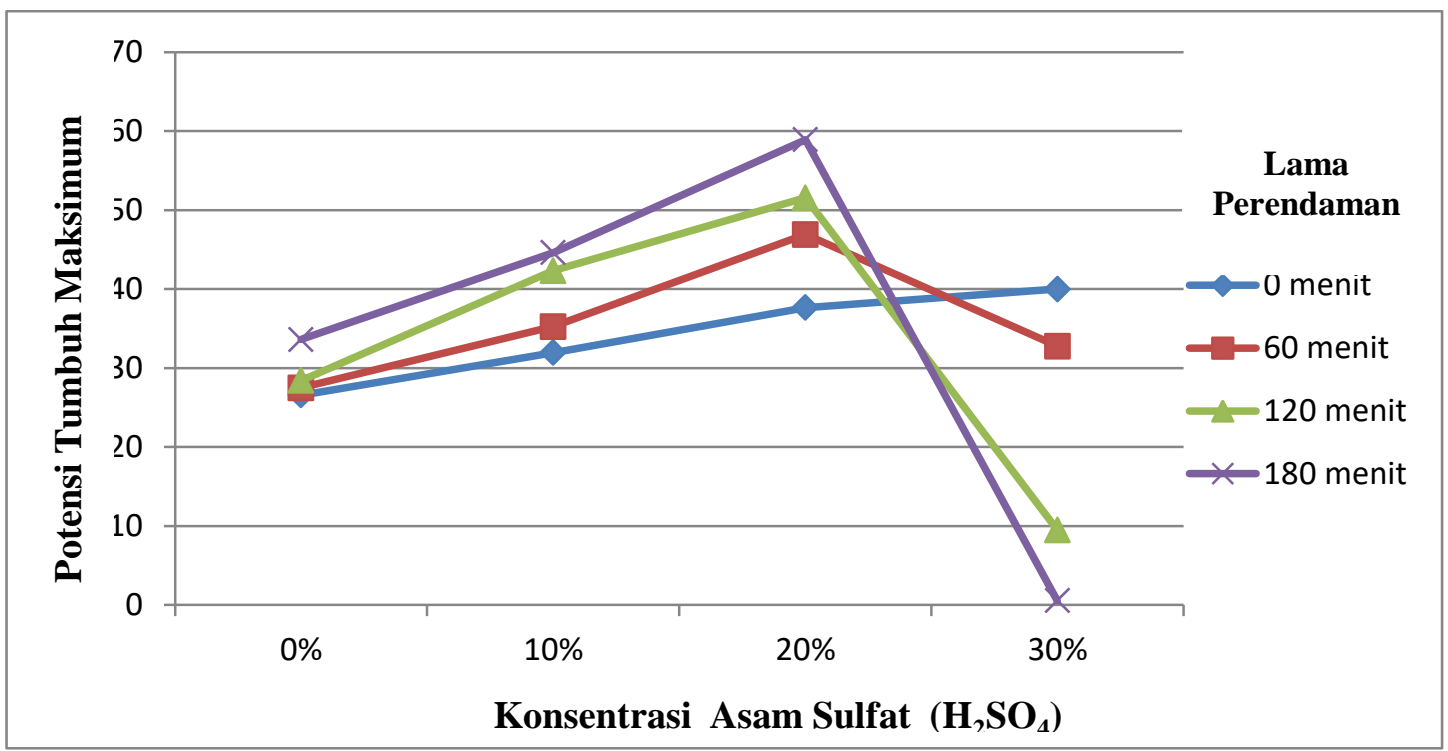

Gambar 1. Interaksi antara lama perendaman benih dalam air panas dan konsentrasi asam sulfat $\left(\mathrm{H}_{2} \mathrm{SO}_{4}\right)$ pada peubah potensi tumbuh maksimum

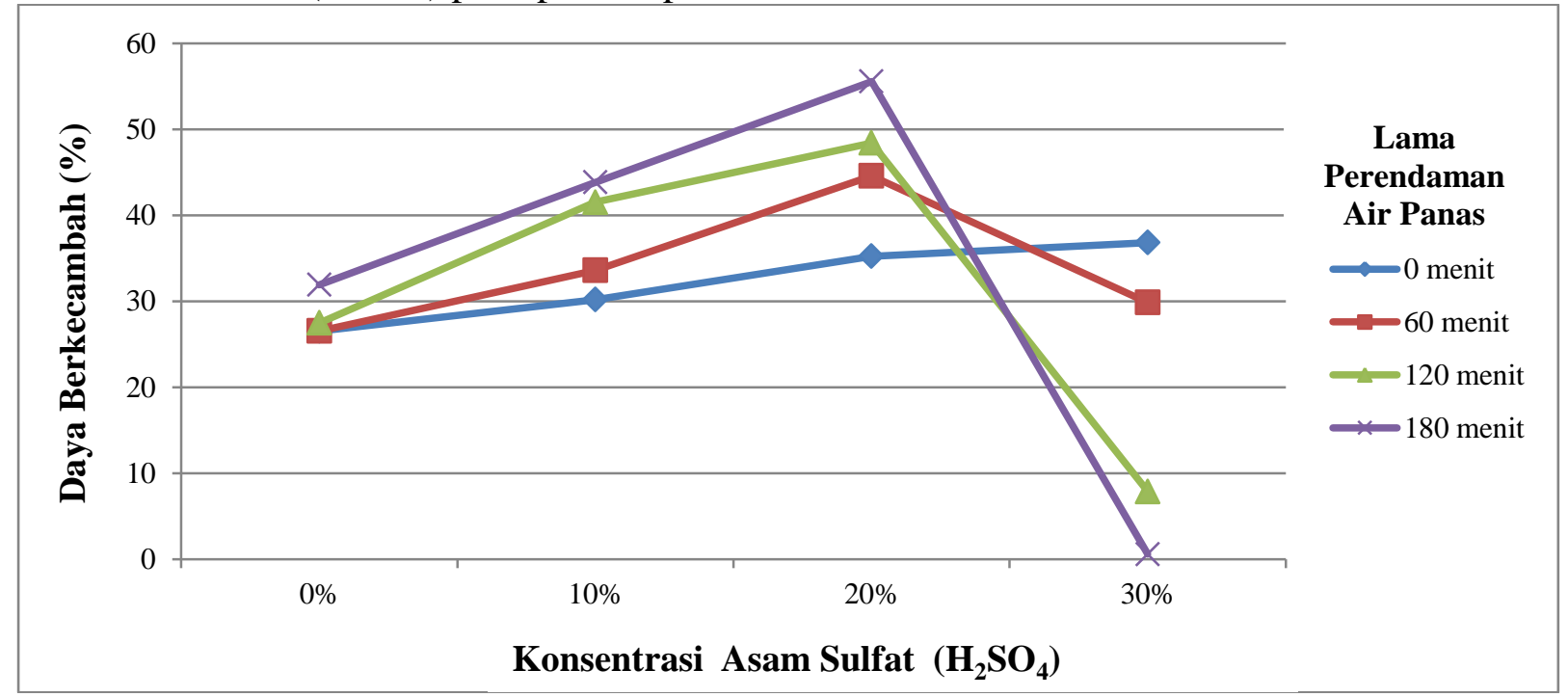

Gambar 2. Interaksi antara lama perendaman benih dalam air panas dan konsentrasi asam sulfat $\left(\mathrm{H}_{2} \mathrm{SO}_{4}\right)$ pada peubah daya berkecambah 


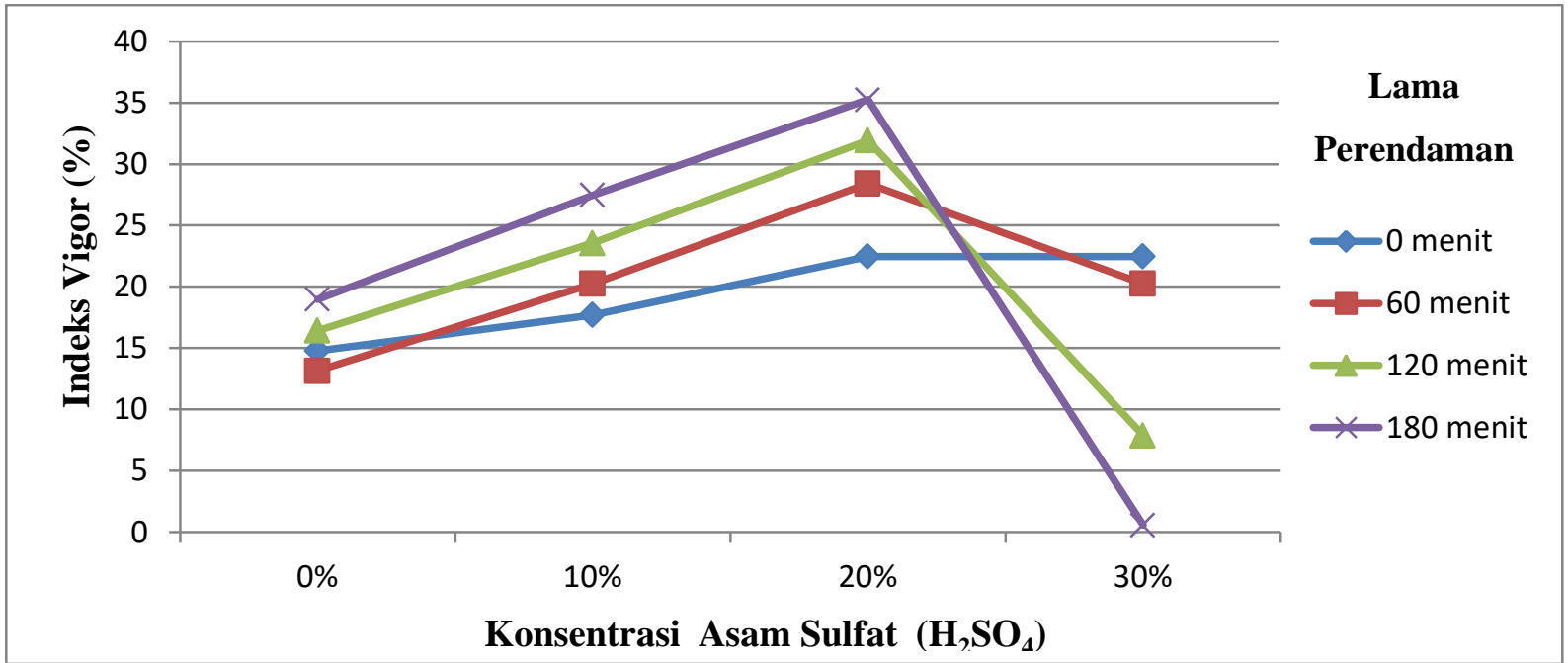

Gambar 3. Interaksi antara lama perendaman benih dalam air panas dan konsentrasi asam sulfat $\left(\mathrm{H}_{2} \mathrm{SO}_{4}\right)$ pada peubah indeks vigor

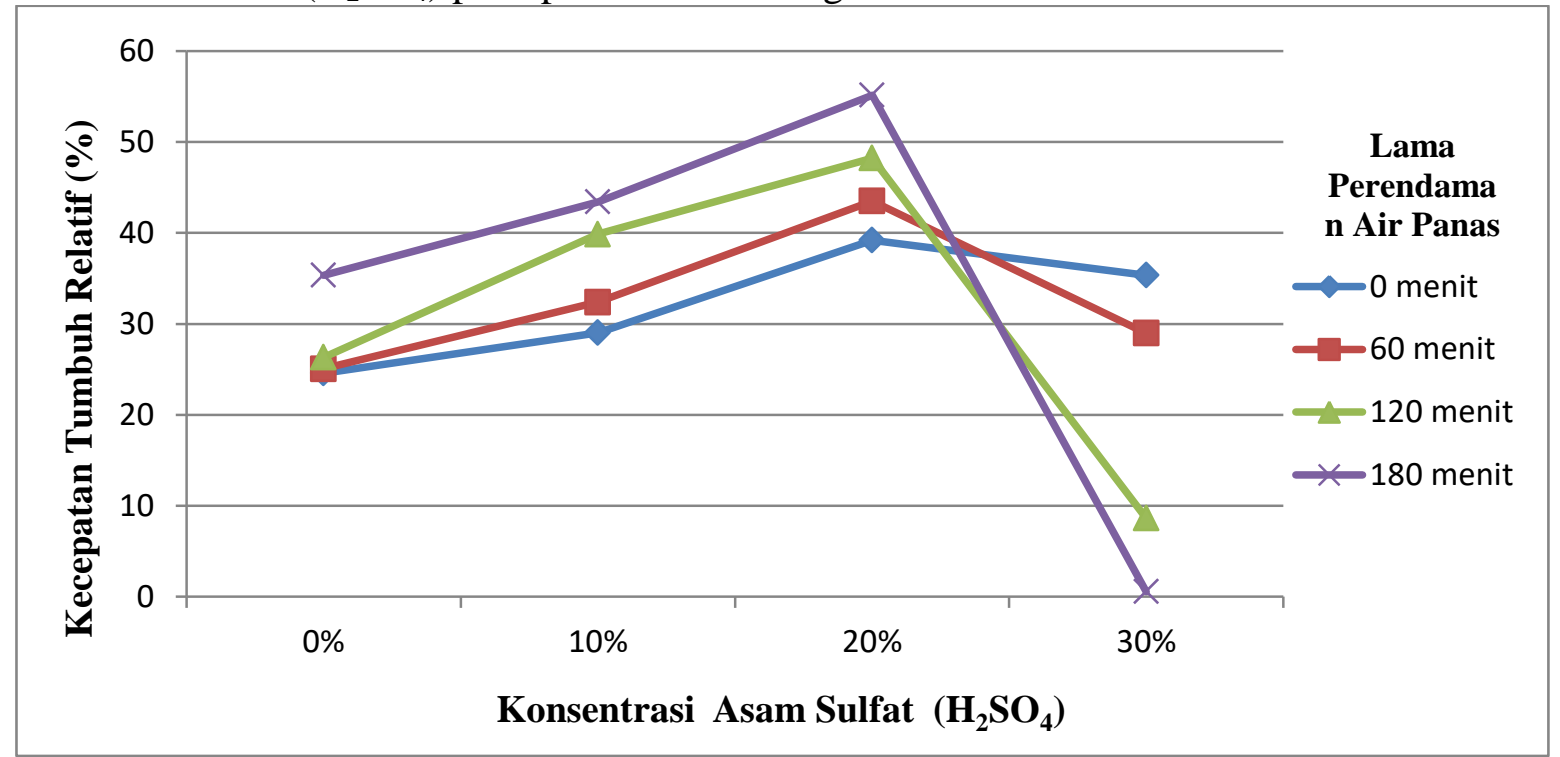

Gambar 4. Interaksi antara lama perendaman benih dalam air panas dan konsentrasi asam sulfat $\left(\mathrm{H}_{2} \mathrm{SO}_{4}\right)$ pada peubah kecepatan tumbuh relatif 


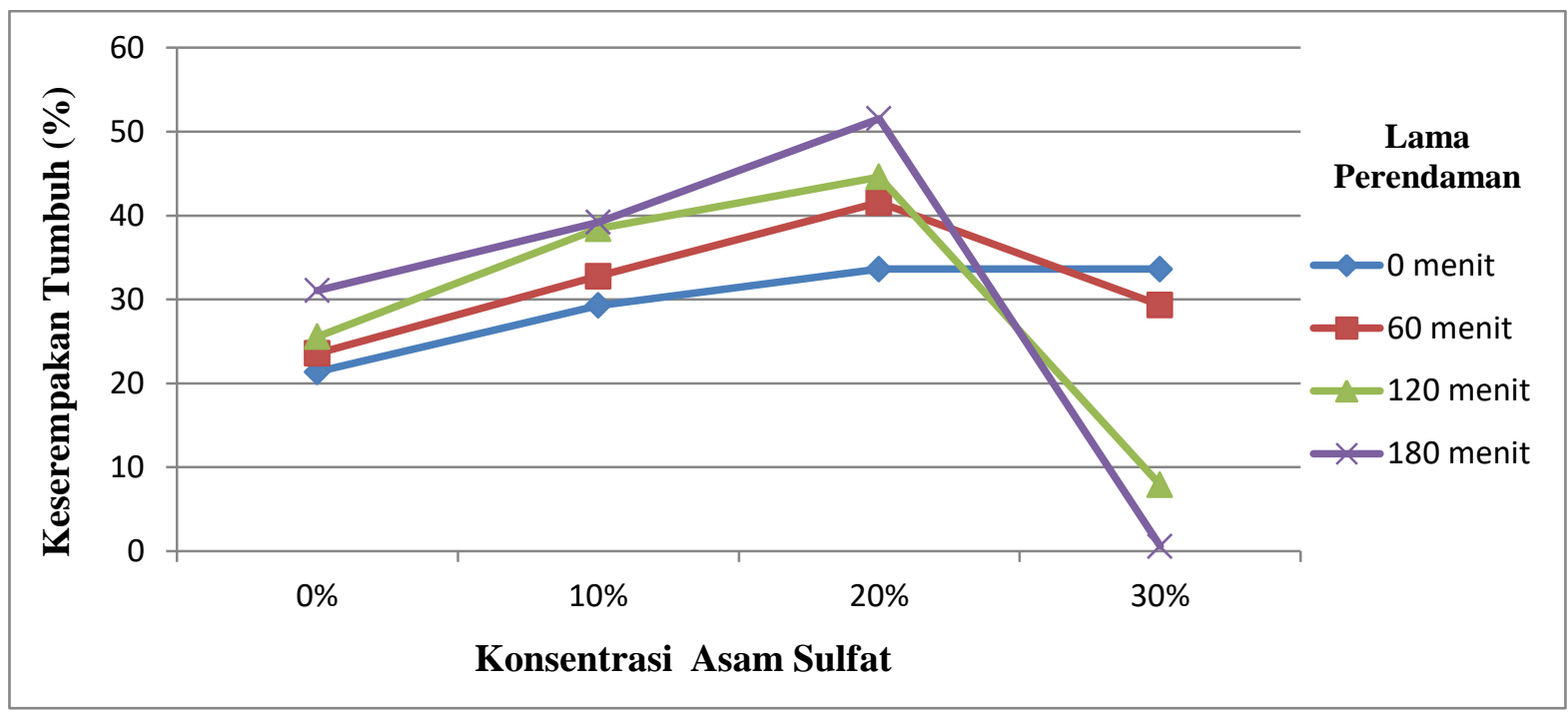

Gambar 5. Interaksi antara lama perendaman benih dalam air panas dan konsentrasi asam sulfat $\left(\mathrm{H}_{2} \mathrm{SO}_{4}\right)$ pada peubah keserempakan tumbuh

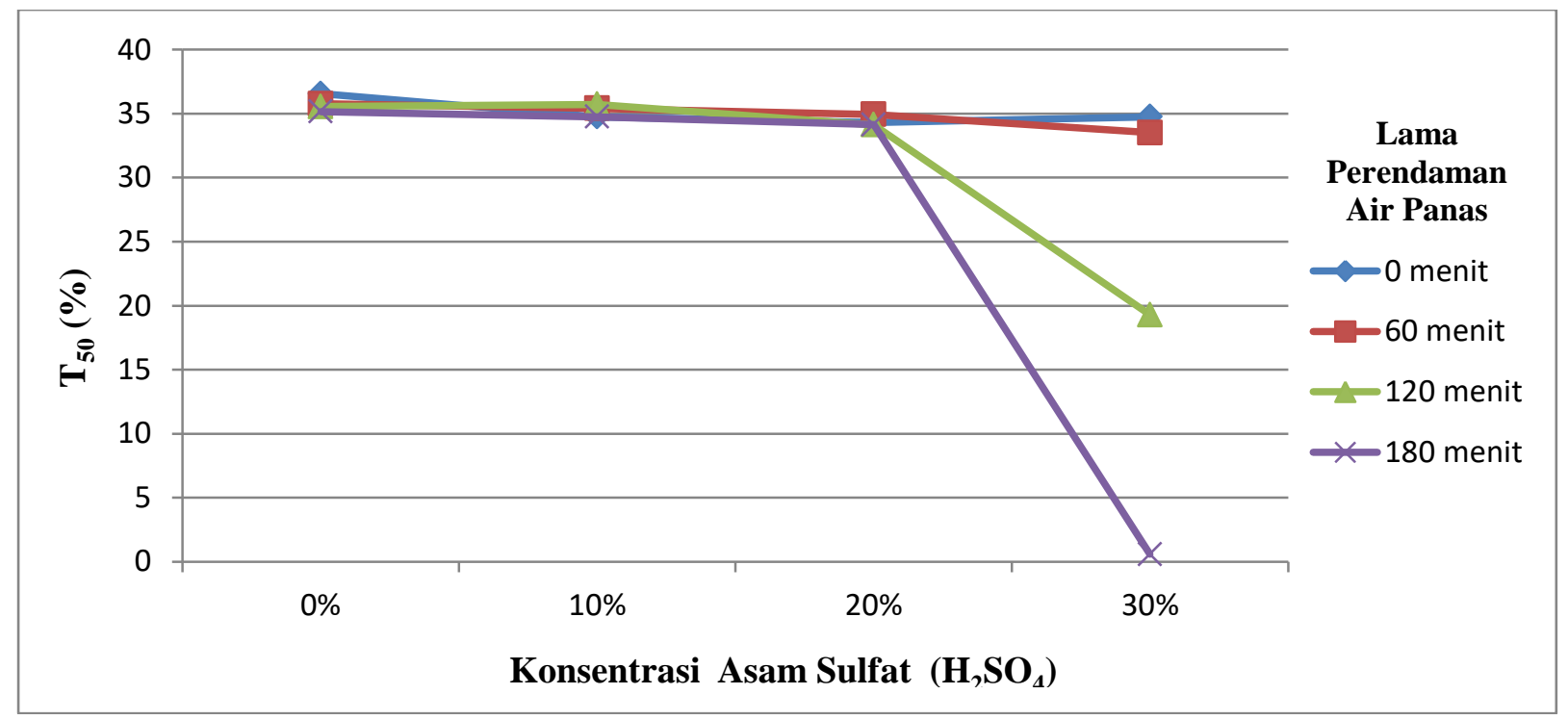

Gambar 6. Interaksi antara lama perendaman benih dalam air panas dan konsentrasi asam sulfat $\left(\mathrm{H}_{2} \mathrm{SO}_{4}\right)$ pada peubah $\mathrm{T}_{50}$ 


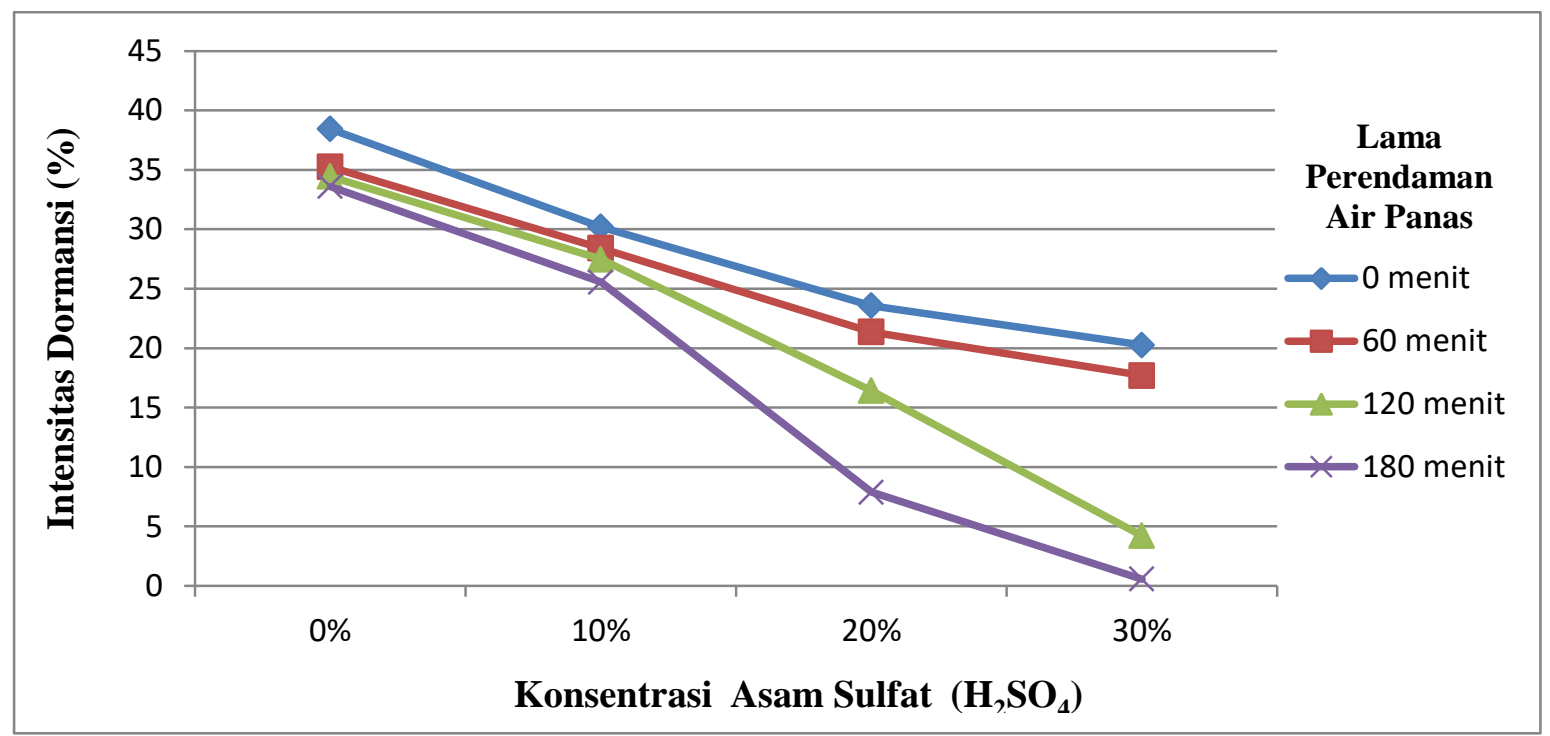

Gambar 7. Interaksi antara lama perendaman benih dalam air panas dan konsentrasi asam sulfat $\left(\mathrm{H}_{2} \mathrm{SO}_{4}\right)$ pada peubah intensitas dormansi

Penggunaan larutan asam sulfat tidak boleh dalam konsentrasi yang berlebihan (dalam penelitian ini $>20 \%$ ), karena akan menurunkan nilai peubah PTM, DB, IV, $\mathrm{K}_{\text {CT-R }}$ dan $\mathrm{K}_{\mathrm{ST}}$. Menurut Purwaning (2009), akibat perlakuan yang over treatment (perlakuan yang berlebihan) akan menyebabkan kerusakan jaringan embrio sehingga benih tidak berkecambah atau mati. Berdasarkan hal tersebut dapat diketahui bahwa konsentrasi asam yang diberikan tergantung pada tingkat ketebalan kulit benih yang akan dipatahkan dormansinya. Ada dua hal yang harus diperhatikan dalam peningkatan konsentrasi asam sulfat yaitu kulit benih dan larutan asam agar tidak mengenai embrio dalam benih.

Tabel 1 menunjukkan bahwa perendaman benih dalam air dengan suhu $60^{\circ} \mathrm{C}$ selama 180 menit dapat meningkatkan waktu yang dibutuhkan untuk mencapai $50 \%$ total perkecambahan $\left(\mathrm{T}_{50}\right)$ menjadi lebih cepat. Waktu yang dibutuhkan untuk mencapai $50 \%$ perkecambahan dapat dihitung berdasarkan gejala tumbuh benih yang berkecambah setiap harinya. Isnaeni dan Habibah (2014) menyatakan bahwa perlakuan perendaman suhu optimal dapat mempengaruhi waktu munculnya kecambah pada benih. Ali et al. (2011) juga menambahkan bahwa mekanisme perkecambahan benih yang dipengaruhi oleh larutan $\mathrm{H}_{2} \mathrm{SO}_{4}$ mampu memecahkan kulit benih yang keras sehingga air dapat masuk kedalam benih. Namun, pada perendaman benih dalam air dengan suhu $60^{\circ} \mathrm{C} \quad(>120$ menit $)$ dan konsentrasi asam sulfat $30 \%$ benih tidak berhasil menjadi kecambah normal, karena pada konsentrasi tersebut terjadi kerusakan embrio pada benih. Hasil penelitian Lensari (2009), menyatakan bahwa pematahan dormansi benih angsana (Plerocarvus indicus Will.) dengan perendaman $\mathrm{H}_{2} \mathrm{SO}_{4}$ pada konsentrasi tinggi dapat menyebabkan laju pertumbuhan benih menjadi menurun.

Perlakuan fisik dengan perendaman benih dalam air dengan suhu $60^{\circ} \mathrm{C}$ selama 180 menit merupakan perlakuan yang terbaik, dimana nilai intensitas dormansi (ID) lebih rendah. Hal ini dapat diasumsikan bahwa semakin rendah nilai intensitas dormansi maka semakin banyak benih yang berkecambah, sebaliknya 
semakin tinggi nilai intensitas dormansi maka semakin banyak benih yang tidak berkecambah. Yuniarti dan Dharmawati (2015) menambahkan perlakuan perendaman dengan air panas yang diikuti dengan perendaman dalam asam sulfat selama 20 menit mampu mematahkan dormansi benih kourbaril (Hymenaea courbaril) dengan daya kecambah $97 \%$ dan kecepatan berkecambahnya $6.47 \%$ dibandingkan dengan yang tidak diberikan perlakuan (kontrol).

\section{KESIMPULAN}

Terdapat interaksi yang sangat nyata antara perlakuan fisik yaitu perendaman dalam air panas suhu $60^{\circ} \mathrm{C}$ dan kimia yaitu pemberian asam sulfat pekat $97 \%$ pada pematahan dormansi benih tanjung terhadap semua parameter viabilitas dan vigor. Kombinasi perlakuan terbaik terdapat pada lama perendaman air panas 180 menit dan konsentrasi asam sulfat $20 \%$ yang ditunjukkan dengan nilai potensi tumbuh maksimum $73.33 \%$, daya berkecambah $68 \%$, indeks vigor $33.33 \%$, kecepatan tumbuh relatif $67.31 \%$, keserempakan tumbuh $61.31 \%$, waktu yang dibutuhkan untuk mecapai 50\% perkecambahan total 31.50 hari dan intensitas dormansi $2.66 \%$.

\section{DAFTAR PUSTAKA}

Ali HH, Tanveer, MA Nadeem, HN Asghar. 2011. Methods to break seed dormancy of Rhynchosia capitata. Chilean Journal of Agricultural Research. 71 (3): 483-487

Ani N. 2006. Pengaruh perendaman benih dalam air panas terhadap daya kecambah dan pertumbuhan bibit lamtoro (Leucaena leucocephala). J. Penelitian
Bidang Ilmu Pertanian. 4 (1): 2428

Fitri N. 2015. Pengaruh skarifikasi dengan perendaman dalam aquades, air panas, dan asam sulfat terhadap perkecambahan biji dan pertumbuhan awal lamtoro (Leucaena leucocephala) [skripsi]. Makassar(ID): Universitas Hasanuddin

Heyne K. 1987. Tumbuhan Berguna Indonesia. Jilid I dan II. Badan Libang Kehutanan, penerjemah. Jakarta(ID): Koperasi Karyawan Departemen Kehutanan. Cetakan I

Isnaeni E, NA Habibah. 2014. Efektifitas skarifikasi dan suhu perendaman terhadap perkecambahan biji kepel (Stelechocarpus burahol (Blume) Hook. F dan Thumpson) secara in vitro dan ex vitro. $J$. MIPA. 37 (2): 105-114

Kurnianingsih N. 2012. Pengaruh suhu dan lama perendaman dalam air terhadap perkecambahan biji ki jijau (Samanea saman) [skripsi]. Malang(ID): Universitas Islam Megeri Maulana Malik Ibrahim Malang

Kurniaty R. 1987. Pengaruh asam sulfat terhadap perkecambahan benih panggal buaya (Maesopsis eminii Engl). Buletin Penelitian Hutan. (488): 35-44.

Lensari D. 2009. Pengaruh pematahan dormansi terhadap kemampuan perkecambahan benih angsana (Pterocarpus indicus Will) [skripsi]. Bogor(ID): Institut Pertanian Bogor

Mai-Hong T, Hong TD, Hien NT, Hai HH, Tung TD, Le-Tam VT, NgocTam B, Ellis R H. 2006. Seed development, maturation and storage behaviour of Mimusops 
elengi L. New Forests, 32 (1): 919

Neto JC. 2000. Germinatif pretreatment to dormancy break in Guazuma ulmifoia Lamk. seed. J. Scientic Forestalis. 58: 15-24

Nugroho TA, Z Salamah. 2015. Pengaruh lama perendaman dan konsentrasi asam sulfat $\left(\mathrm{H}_{2} \mathrm{SO}_{4}\right)$ terhadap perkecambahan biji sengon laut (Paraseriathes falcataria). JUPEMASI-PBIO. 2 (1): 230236.

Oben, A Bintaro, M Riniarti. 2015. Pengaruh perendaman benih pada berbagai suhu awal air terhadap viabilitas benih kayu afrika (Maesopsis eminii). J. Sylva Lestari. 2 (1): 101-108

Purwaning D. 2009. Struktur benih dan dormansi pada benih pangkal buaya (Zanthoxylum rhetsa (Roxb.). J. Manajemen Hutan Tropika. 15 (2): 66-74

Puspitarini DP. 2003. Struktur benih dan dormansi pada benih panggal buaya (Zanthoxylum rhetsa (Roxb).D.C) [tesis]. Bogor(ID): Institut Pertanian Bogor

Rahayu A. 2013. Viabilitas dan vigor benih aren (Arenga pinnata) akibat pematahan dormansi melalui skarifikasi secara fisik dan kimia [skripsi]. Banda Aceh(ID): Universitas Syiah Kuala

Rozi F. 2003. Pengaruh perlakuan pendahuluan dengan peretakan, perendaman air $\left(\mathrm{H}_{2} \mathrm{O}_{2}\right)$, asam sulfat $\left(\mathrm{H}_{2} \mathrm{SO}_{4}\right)$, dan hormon giberelin $\left(\mathrm{GA}_{3}\right)$ terhadap viabilitas benih Kayu Afrika (Haesopsis eminii Engl) [skripsi]. Bogor(ID): Institut Pertanian Bogor
Sandi ALI, Indriyanto, Duryat. 2014. Ukuran benih dan skarifikasi dengan air panas terhadap perkecambahan benih pohon kuku (Pericopsis mooniana). J. Sylva Lestari. 2 (3): 82-92

Suyatmi, ED Hastuti, S Darmanti. 2011. Pengaruh lama perendaman dan konsentrasi asam sulfat $\left(\mathrm{H}_{2} \mathrm{SO}_{4}\right)$ terhadap perkecambahan benih jati (Tectona grandis Linn.). Buletin Anatomi dan Fisiologi. 19 (1): 28-36

Widhityarini D, MW Suyadi, P Aziz. 2013. Pematahan dormansi benih tanjung (Mimusops elengi L.) dengan skarifikasi dan perendaman larutan kalium nitrat $\left(\mathrm{KNO}_{3}\right)$. J. Vegetalika.1: 1-12

Winarni E. 2010. Daya berkecambah benih tanjung pada berbagai kadar air benih. Jurnal Hutan Tropis. 11 (30) : 12-24

Yuniarti N, DF Dharmawati. 2015. Teknik pematahan dormansi untuk mempercepat perkecambahan benih kourbaril (Hymenaea courbaril). Pros Sem Nas Masy Biodiv Indon. 1 (6): 1433-1437 